Boletín de la Sociedad Geológica Mexicana

VOLUMEN 64, NÚM. 1, 2012, P. 155-159

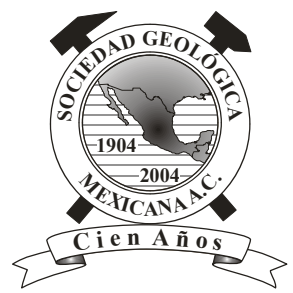

\title{
Bite marks of a large theropod on an hadrosaur limb bone from Coahuila, Mexico
}

\author{
Hector E. Rivera-Sylva $a^{1, *}$, David W.E. Hone ${ }^{2}$, Peter Dodson ${ }^{3}$ \\ ${ }^{1}$ Departamento de Paleontología, Museo del Desierto, Carlos Abedrop Dávila 3745, Saltillo, Mexico \\ ${ }^{2}$ School of Biology and Environmental Sciences, University College Dublin, Dublin 4, Ireland \\ ${ }^{3}$ Department of Earth and Environmental Science, University of Pennsylvania, 240 South $33^{\text {rd }}$ Street, Philadelphia, PA 19104, U.S.A. \\ *hrivera@museodeldesierto.org
}

\begin{abstract}
We describe theropod bite marks on the tibia of a hadrosaurine ornithopod recovered northwest of Coahuila, Mexico. Based on the size and shape of the bites, these marks are attributed to a tyrannosaurine. The finding provides support for recent hypotheses on theropod feeding behavior and palaeoecology.
\end{abstract}

Keywords: Tyrannosaurine, palaeoecology, feeding, behavior, Ornithischian.

Resumen

Aqui describimos marcas de mordidas de téropodo en la tibia de un ornitópodo hadrosaurino encontradas en el noroeste de Coahuila, México. Basados en el tamaño y forma de las mordidas, estas marcas son atribuidas a un tyrannosaurino. El descubrimiento provee apoyo a recientes hipótesis sobre la paleoecología y comportamiento alimenticio de los terópodos.

Palabras clave: Tyrannosaurino, paleoecología, comportamiento, alimenticio, Ornitisquio.

\section{Introduction}

Evidence of direct interactions between carnivorous dinosaurs and their food is rare in the fossil record. Although some examples of predation (e.g., Matthew, 1908; Farlow, 1976; Carpenter, 1998), feeding (Erickson and Olson, 1996; Fowler and Sullivan, 2006), and scavenging (Hone and Watabe, 2010; Hone et al., 2010) are known for theropod dinosaurs, bite marks remain generally rare (Hone and Rauhut, 2010). Therefore, it is important to report new finds. Here we describe bite marks on the tibia of a hadrosaur found in the late Campanian Agua Formation at the La Salada locality, northwestern Coahuila.

The fossil record of carnivorous theropod dinosaurs suggests that the taxonomic composition of dinosaurian predator-prey systems varied notably as a function of time and geography (Farlow and Holtz, 2002; Larson, 1998). Details regarding dietary and hunting behaviours of theropods can be inferred from their functional morphology, supported by evidence from taphonomic associations with likely prey species, bite marks, gut contents, coprolites, and trackways (e.g., see Hone et al., 2010). However, tooth marks in fossilised bones are direct evidence for inferring trophic interactions (Longrich and Ryan, 2010). Farlow and Holtz (2002) suggest that there are major morphological differences among taxa which presumably reflect differences in attacking and feeding behaviour and/ or diets, corroborated by trace fossils. Indeed, inferences about specific feeding behaviours can be made from certain exceptional bite-mark traces (e.g. see Erickson and Olson, 
1996; Hone and Watabe, 2010).

Some fossils show active predation by theropods upon herbivorous dinosaurs, such as a Hypacrosaurus leg bone with a theropod tooth embedded within it (Farlow and Holtz, 2002). Late-stage carcass consumption of largely inaccessible specimens also shows definitive evidence of scavenging of already dead prey (Hone and Watabe, 2010). The reality is however, that most theropods were likely both: predators and scavengers (Carpenter, 1998; Holtz, 2008; Hone et al., 2010; Longrich and Ryan, 2010).

\subsection{Palaeoecology and environmental context at La} Salada

The first field team to discover dinosaur remains in the northwest of the state of Coahuila, México, belonged to the National Institute of Statistics, Geography and Informatics (INEGI, its acronym in Spanish) in 1996. They contacted and took H.E.R.-S. to the fossiliferous sites in 2007. The assemblage at La Salada (Late Cretaceous, Campanian) contains numerous microvertebrate fossils including gar fish scales and turtle osteoderms of the Trionychidae clade (Rivera-Sylva et al., 2007). All the localities are in the municipality of Ocampo, northern Coahuila.

The presence of trionychid turtles provides evidence for a large coherent freshwater system with large low energy river sections and deep oxbows (Ernst and Barbour, 1989). Trionychid turtles may occur in brackish waters but need sandy open riverbanks with shallow shores for breeding. Furthermore, trionychids mainly prey on fishes and other vertebrates as well as a variety of invertebrates, the presence of which has to be proved by further investigations, especially through screen washing. The giant alligatoroid Deinosuchus riograndensis is also present in the assemblage and like trionychid turtles, Deinosuchus needed shallow beaches with sand or soil coverage for nesting (RiveraSylva et al., 2011). Ceratopsians and hadrosaurines make up the known terrestrial biota of the dinosaurian component of the assemblage (Rivera-Sylva et al., 2007). Based on the available material, hadrosaurs appeared to have been the most abundant of the terrestrial mega-vertebrates. Hadrosaurines are known from disarticulated, but complete long bones, including the tibia in which the bite marks were found. There are currently no records of theropod bones or teeth at this locality.

\section{Locality Information}

The locality of La Salada is in northwestern Coahuila, and is part of the Aguja Formation (late Campanian). The vertebrate fossils found in the locality comprise elements from both aquatic and terrestrial taxa and thus lines up with other coeval localities further North. Elements from hadrosaurine specimens occur both above and below a ceratopsian bed in the section, suggesting several depositional events.

Lithology, sedimentology and geomorphology confirm coastal habitational types. The freshwater system was situated on a coastal plain which drained as a delta into the Paleo-Gulf of Mexico (Monreal and Longoria, 2000). Further exploration will yield more material for a detailed reconstruction of local types of habitat in the system as well as its geographical and temporal extension.

\section{Description}

The specimen was found on March 2011, in association with a partial fibula and a dorsal vertebra. The specimen was prepared by air scribe and the bite marks with dental instruments. Specimen CPC $789 / 1$ is identified as a hadrosaur's left tibia and is $1.14 \mathrm{~m}$ long with expanded proximal and distal ends (Figure 1 A, B). The bone is nearly complete although some fragments were lost before burial. The proximal end possesses two condyles, the medial being the larger. The cnemial crest extends craniolaterally from the medial tibial condyle. Distally, the shaft twists outwardly at about $45^{\circ}$ so that the distal end of the tibia is not oriented forward but rather is splayed to the side. The distal craniolateral face is flattened and divided by a moderately deep depression, while the caudomedial face's outline is convex (Lull and Wright, 1942; Horner et al., 2004). Based on comparison with other specimens in the Paleontological Collection of Coahuila, the tibia would appear to belong to a subadult individual of around $8 \mathrm{~m}$ in length.

On the distal end of the tibia there are two sets of bite marks. The first consists of four sub-parallel traces on the craniolateral face of the bone (Figure 1C). These marks are short (ranging from 2-12 mm long and 1-2 mm deep), but are quite broad. Following the definitions of Hone and Watabe (2010) these are considered drag marks: shallow marks that drag along the bone surface and do not penetrate the cortex. However it is possible that part of the cortex, distal to these marks, has broken free of the bone due to the marks as a whole being somewhat indistinct without "clean" edges, possibly through erosion.

A second set of three marks lies on the caudomedial face of the tibia (Figure 1D). These are longer and thinner, and are more clearly defined that the set described above. The first two are larger (23 and $34 \mathrm{~mm}$ long and $2 \mathrm{~mm}$ deep) than the third (just $7 \mathrm{~mm}$ long and only $1 \mathrm{~mm}$ deep). In each of the two sets the spacing between each individual mark is around $10 \mathrm{~mm}$.

\section{Discussion}

The bite marks seen on CPC 789/1 are linked to a tyrannosaurine theropod based on their size and spacing. The morphology of both sets of marks is similar to other bite marks referred to large tyrannosaurines (e.g., Fowler 


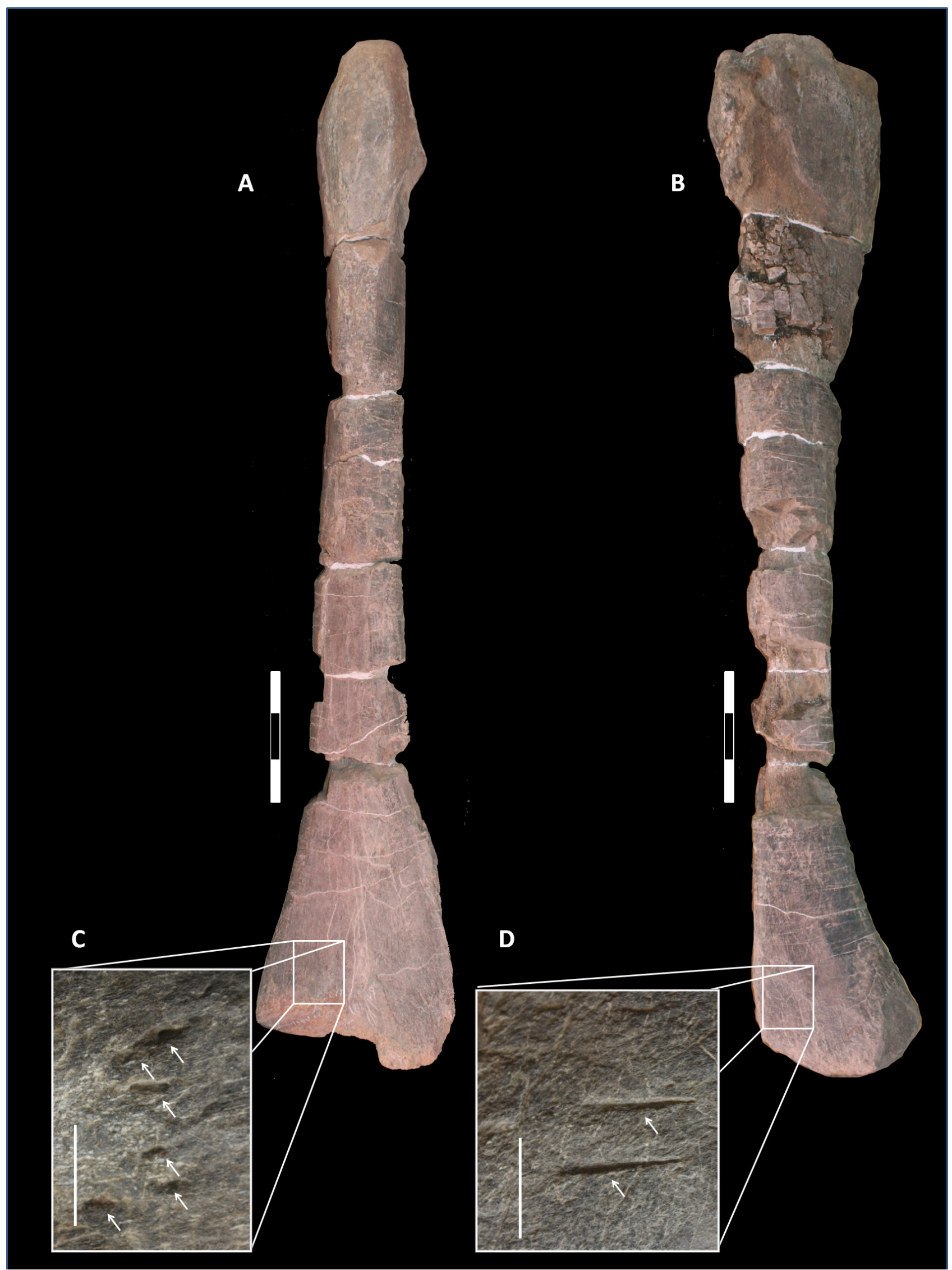

Figure 1. Hadrosaur left tibia CPC 789/1. Shown in A) Craniolateral view and B) craniomedial view. Close-ups of the bite marks are indicate in C and D. Scale bars are $15 \mathrm{~cm}$ for $\mathrm{A}$ and $\mathrm{B}$, and $3 \mathrm{~cm}$ for $\mathrm{C}$ and $\mathrm{D}$ 
and Sullivan, 2006; Hone and Watabe, 2010). In the Late Cretaceous of North America, only tyrannosaurines reach especially large sizes such that there is often a large discontinuity of adult sizes between the tyrannosaurines and the next largest carnivorous dinosaurs in the fauna (generally dromaeosaurids and troodontids), rather than the gradational distribution of adult sizes seen in non-tyrannosaurinedominated faunas, or multiple large theropods of different clades (Hone et al., 2011).

This is the second record of a bone bearing bite marks for the locality (Rivera-Sylva et al., 2009a), but this is the first attributed to a dinosaur. This also represents the first record of a tyrannosaurine in this locality, though a tyrannosaurid tooth is known from a nearby locality of the same formation (Rivera-Sylva et al., 2009b).

These bites are considered post-mortem because there is no evidence of healing and the locations (distal tibia) are not a likely point for a strike during attempted predation. In the case of the craniolateral marks, the fibula would likely have obstructed a bite, and the bites are shallow and not deep, penetrating marks as seen in the Hypacrosaurus example (Farlow and Holtz, 2002). The location of these bites on the tibia and the lack of other marks (especially punctures) supports relatively early stage carcass consumption. Although the distal tibia would have less muscle mass associated with it than the proximal part, the hindlimbs in general would normally be a relatively early part of carcass consumption. The position and morphology of the two sets of bite marks are consistent with the inferences of Hone and Watabe (2010) for feeding with premaxilary teeth only, given the limited number of scrape marks and the lack of corresponding marks on the opposite face of the tibia to each set. Furthermore, there are no signs of dismembering of the joints as seen in feeding patterns of a hadrosaur humerus (Hone and Watabe, 2010). This is also consistent with the suggestions by Hone and Rauhut (2010) of theropods were quite careful feeders. Only two small sets of shallow marks have been made here despite the fact that the inference of early stage carcass consumption would mean the carnivore would have been able to feed extensively on the body but without at least leaving any further traces on the tibia.

Hadrosaur bones show bite marks more frequently than do the bones of other herbivorous dinosaurs (Farlow and Holtz, 2002). Jacobsen (1998) recorded up to $14 \%$ of hadrosaur bones showing feeding traces in one bone bed, so further specimens are to be expected at this and other localities in the formation.

\section{Acknowledgements}

We would like to thank the following individuals for their contribution to this project: Rubén Guzmán, Jorge Ortiz, Artemiza González, Brandon Hedrick, Susie Maidment, and Iván Sanchez. We are also indebted to
Homero Hernández for finding the specimen and Abraham Isaí Oyervidez for preparing it. Also we want to thank Daniel Posada for the photographs. We thank the COECyT and Museo del Desierto for supporting this investigation. Our special thanks go to the authorities of Ocampo for their kind assistance and support to the Coahuila's Desert Dinosaur Project.

\section{References}

Carpenter, K., 1998, Evidence of predatory behavior by carnivorous dinosaurs: Gaia: Aspects of Theropod Paleobiology, 15, 135-144.

Erickson, G.M., Olson, K.H., 1996, Bite marks attributable to Tyrannosaurus rex: preliminary description and implications: Journal of Vertebrate Paleontology, 16, 175-178.

Ernst, C.H., Barbour, R.W, 1989, Turtles of the World: Washington, D.C., E.UA., The Smithsonian Institution Press, 313 p.

Farlow, J., 1976, Speculations about the diet and foraging behavior of large carnivorous dinosaurs: American Midland Naturalist, 95, 186-191.

Farlow, J., Holtz, T.R.Jr., 2002, The Fossil Record of predation in dinosaurs: Paleontological Society Papers, 8, 251-265.

Fowler, D.W., Sullivan, R.M., 2006, A ceratopsid pelvis with toothmarks from the Upper Cretaceous Kirtland Formation, New Mexico: Evidence of Late Campanian tyrannosaurid feeding behavior, in Lucas, S.G. and Sullivan, R.M. (eds.) Late Cretaceous vertebrates from the Western Interior: Albuquerque, New Mexico, E.U.A., New Mexico Museum of Natural History and Science Bulletin, $35,127-130$.

Holtz, T.R. 2008. A critical reappraisal of the obligate scavenging hypothesis for Tyrannosaurus rex and other tyrant dinosaurs, Tyrannosaurus rex the Tyrant King, in Larson, P. and Carpenter, K. (eds): Bloomington, Indiana, E.U.A., Indiana University Press, 371-396.

Hone, D.W.E., Rauhut, O.W.M., 2010, Feeding behaviour and bone utilization by theropod dinosaurs, Lethaia, 43, 232-244.

Hone, D.W.E., Watabe, M., 2010, New information on scavenging and selective feeding behavior of tyrannosaurs: Acta Paleontologica Polonica, 55, 627-634.

Hone, D.W.E., Choiniere, J., Sullivan, C., Xu, X., Pittman, M., Tan, Q., 2010, New evidence for a trophic relationship between the dinosaurs Velociraptor and Protoceratops: Palaeogeography, Palaeoclimatology, Palaeoecology, 291, 488-492.

Hone, D.W.E., Wang, K. Sullivan, C., Zhao, X., Chen, S., Li, D., Ji, S., Ji, Q., Xu, X., 2011, A new, large tyrannosaurine theropod from the Upper Cretaceous of China: Cretaceous Research, 32, 495-503.

Horner, J., Weishampel, D.B., Forster, C.A., 2004, Hadrosauridae, in Weishampel, D.B., Dodson, P., Osmólska, H. (eds.), The Dinosauria: Berkeley, California, E.U.A., University of California Press, 438463.

Jacobsen, A.R., 1998, Feeding behavior of carnivorous dinosaurs as determined by tooth marks on dinosaur bones: Historical Biology, 13, 17-26.

Larson, P.L., 1998, The king's new clothes: a fresh look at Tyrannosaurus rex, in Wolberg, D.L., Stump, E., Rosenberg, G.D., Dinofest International Proceedings, Academy of Natural Sciences, Philadelphia, 65-72.

Longrich, N.R., Ryan, M.J., 2010, Mammalian tooth marks on the bones of dinosaurs and other Late Cretaceous vertebrates: Palaeontology, 53, 703-709.

Lull, R.S., Wright, N.R., 1942, Hadrosaurian dinosaurs of North America: Geological Society of America Special Paper, 40, 242.

Matthew, W., 1908, Allosaurus, a carnivorous dinosaur, and its prey: American Museum Journal, 8, 2-5.

Monreal R., Longoria, J.F., 2000, Stratigraphy and structure of the Lower Cretaceous of Lampazos, Sonora, (Northwest Mexico) and its relationship to the Gulf Coast Succession: American Association of Petroleum Geologists Bulletin, 84, 1811-1831. 
Rivera-Sylva, H.E., Guzmán-Gutiérrez, R., Palomino-Sánchez, F., LópezEspinosa, J., de la Peña Oviedo, I. 2007, New Vertebrate Fossil Locality from the Late Cretaceous of Northern Coahuila, México: Journal of Vertebrate Paleontology, 27, 135A.

Rivera-Sylva, H.E., Frey, E., Guzmán-Gutiérrez, J.R., 2009a, Evidence of predation on the vertebra of a hadrosaurid dinosaur from the Late Cretaceous (Campanian) of Coahuila, Mexico: Carnets de Géologie, 2, 1-6.

Rivera-Sylva, H.E., Frey, E., Palomino-Sánchez, F., Guzmán-Gutiérrez, R., Ortíz-Mendieta, J.A., 2009b, Preliminary Report from a Late Cretaceous Vertebrate Fossil Assemblage in Northwestern Coahuila, Mexico: Boletín de la Sociedad Geológica Mexicana, 61, 239-244.
Rivera-Sylva, H.E., Frey, E., Guzmán-Gutiérrez, R., Palomino-Sánchez, F., Stinnesbeck, W.A., 2011, Deinosuchus riograndensis (Eusuchia: Alligatoroidea) from Coahuila, Mexico: Revista Mexicana de Ciencias Geológicas, 28, 267-274.

Manuscript received: July 15, 2011.

Corrected manuscript received: February 3, 2012.

Manuscript accepted: February 9, 2012. 